\title{
Evaluation of Clinical Learning Experience on Concept Mapping for Final Year Nursing Students in a Private Hospital
}

\section{Ong So Tiap ${ }^{\mathbf{1}}$, Hassan $\mathbf{H}^{\mathbf{1}}$, Tee $\mathbf{M H}^{\mathbf{2}}$ and Mohd Rosli RA}

${ }^{1}$ School of Nursing, KPJ Healthcare University College, Nilai Negeri Sembilan, Malaysia

${ }^{2}$ School of Medical, USM, Kubang Kerian, Kelantan, Malaysia

${ }^{3}$ KPJ Perdana Specialist Hospital, Kota Bharu, Kelantan, Malaysia

"Corresponding author: Ong So Tiap, School of Nursing, KPJ Healthcare University College, Nilai Negeri Sembilan, Malaysia, Tel: 097458000; E-mail: ongsotiap@yahoo.com

Received date: Sep 04, 2018; Accepted date: Oct 26, 2018; Published date: Oct 31, 2018

Copyright: $@ 2018$ Tiap OS, et al. This is an open-access article distributed under the terms of the Creative Commons Attribution License, which permits unrestricted use, distribution, and reproduction in any medium, provided the original author and source are credited.

\begin{abstract}
Aim: The present study is to apply concept mapping into the learning strategy in the clinical areas for the final semester nursing students understanding of patient care and patient safety process.

Objectives: To compare students' level of understanding knowledge on concept mapping between control and experimental group post intervention training; to determine on the impact of training of concept mapping on students' confidence level in the clinical areas; To determine students' understanding on the application of knowledge in patient care using concept mapping in the clinical areas; to determine on students' satisfaction level learning through concept mapping in the clinical areas.
\end{abstract}

Methods: This is a case study of a group of students in the final year of the diploma in nursing program. It is a classic experimental design that consists of experimental and control group.

Results: This research has given a positive impact to prove that after the intervention of concept mapping for the last year's nursing student showed significant interrelationships. Intervention concept mapping can enhance the learning more meaningful and can be improve through their motivation, sharpens thinking, deepens stimulate higher learning and thinking processes with all items to be measured in the evaluation of the $\mathrm{CM}$. From the point of realized by students, it can have implications for clarifying the learning objectives, refining instructional strategies, identifying appropriate assessment tools, understanding how the learning objectives are being and meanings to the clinical practice of decision-making.

Conclusion: Concept mapping is a learning strategy in the clinical areas for the final semester nursing students understanding of patient care and patient safety process. The CM is established as a significant strategy as well as an approach to assimilate matters involved in the teaching and learning practises of the clinical region.

Keywords: Concept mapping; Nursing education; Clinical teaching; Learning strategy

\section{Introduction}

The clinical learning is a major part of nursing education. Lack of students' exposure to the clinical learning environment is one of the most important factors affecting the teaching-learning process in clinical settings. Unlike classroom education, clinical training in nursing occurs in a complex clinical learning environment which is influenced by many factors. This environment provides an opportunity for nursing students to learn experimentally and to convert theoretical knowledge to a variety of mental, psychological, and psychomotor skills which are of significance for patient care.

A decisive aspect of having positive learning experiences is described to be the relationship between the student and the nurse supervisor [1]. Regular feedback, reflections, and practical advice from the supervisor are very important factors for improving the students' practical competence, confidence, motivation, and self-esteem [2].
Interpersonal relationships between students and health care providers was said to be one of the students' satisfaction learning in the clinical areas. Patients, peer, ward staff mentor and nursing instructors are the major stakeholders involved to provide experience-rich and supportive relationship.

High levels of satisfaction have been reported when students had someone to ensure that their learning needs were addressed, when the clinical staffs were well briefed, when the students were treated with respect and appreciated as well, it and being included as part of the health care team.

Other factors that affect students learning experience in the clinical areas are the effective clinical teachers. It requires an expert in the substantive areas, good instructional skills (e.g.) well organized; explanations are clear and understood by students. The nursing instructors should have strong interpersonal and communication skills to serve as a role model for students and new graduates, besides being enthusiastic and motivated. Equally important are the abilities to assess the learning and performance in all learning areas such as; the simulation and skills lab, and the clinical setting [3]. 
This paper reports findings from a research project that was undertaken in one of the private hospital in Malaysia to enhance application of concept mapping into the learning strategy in the clinical areas for the final semester nursing students' understanding of patient care and patient safety process. This paper focuses on the results pertinent to the following questions:

- What is the overall learning experience of the final year nursing students in transforming the knowledge of patient care after using the concept mapping approach in the clinical areas?

- What is the overall impact on training of concept mapping on student's confidence level of the final year nursing students in transforming the knowledge of patient care after using the concept mapping approach in the clinical areas?

- What is the difference in level of experience of each student learning after the application of concept mapping?

- What is the relationship between the learning experience of application of knowledge of patient care and the rest of the learning experiences?

\section{Literature Review}

Description studies on the use of concept mapping in clinical teaching were reviewed. The literature review includes:

- The effectiveness of concept mapping as a teaching method for nursing students.

- $\quad$ Concept mapping in the clinical setting.

- $\quad$ Process of learning and concept mapping.

- Critical thinking and concept mapping and the conclusion.

\section{Effectiveness of concept mapping as teaching instrument}

Several research studies have reported the effectiveness of concept mapping as teaching/learning methods in nursing. Rooda et al. [4] explored the use of concept mapping with final year students in a research course. This study noted increased academic performance in the experimental group that used concept mapping as opposed to a control group.

Better educated nurses with complex skills and abilities are required to deliver safe and quality patient care in a health care system that continually changes as per the National Advisory Council on Nurse Education and Practice $[5,6]$.

Nursing graduates need to be prepared to not only be compassionate caregivers, but need to be highly skilled problem solvers and critical thinkers. Nursing graduates also need to be culturally competent to care for a diverse population and technologically practicality to meet the advancing technological health care system.

Concept mapping reveals the process can have a powerful effect on learning. Concept mapping can move learners toward more in-depth learning, such as meaningful learning, by facilitating the process of linking new concepts with existing knowledge and experience found students who created a concept map while taking notes had a better test recall, able to access information more quickly during tests, scored better on content posted than students who did not have the concept mapping experience [7,8]. Therefore, concluded that the understanding of the students' care plans could be improved when they see a representation of the main concepts and relationships between those concepts. With that the researchers are of the opinion that as the nursing care in the community is often complex in nature and changes in each setting time. The researchers agreed and decided that concept mapping is an effective learning instrument to help students apply new knowledge and skills to clients with healthcare needs in a clinical setting. Students can be served better if they are helped to learn how to process new information rather than to memorize cares that are required in a specific setting.

In Malaysia, participants in a study were a heterogeneous group of students consisting $(\mathrm{n}=47)$ for Master Program in Technical and Vocational Education at the University Tun Hussein Onn Malaysia was conducted applying concept map. Though, these are not nursing students, as studies with concept maps for nursing students are still very sparse and limited in Malaysia.

\section{Concept mapping in the clinical setting}

Concept maps could be useful in student preparation for clinical experiences. It could be taught to nursing students to assist them in organizing the data obtained in pre-planning for clinical experience and then presented at pre- and/or post-clinical conferences.

The only instructions that these particular students were given about constructing a map were:-

- There was no right or wrong way to do the map.

- The map should be what they felt was useful information.

- To take risks and try out different representations.

The processing of information that occurs during concept map construction requires and encourages meaningful learning.

\section{Process of learning and concept mapping}

Concepts and propositions are organized with the most general, most important concepts at the top of the map, and with progressively more specific, less important concepts lying under the more inclusive concepts. The specific structure is context-dependent. Map construction is done by identifying relevant concepts in the material.

\section{Critical thinking and concept mapping}

Nursing educators agreed that critical thinking is needed and should be taught and developed in nursing school. As there are varieties of teaching methods of critical thinking, there is a need for educators understand which pattern or strategies are the best and most effective. In their studies, Kostovich and Pudelko et al. $[9,10]$ have proposed that it is good to identify the learning styles of students would be beneficial in understanding what strategies would promote critical thinking development in nursing students.

Critical thinking in nursing for clinical decision-making is the ability to think systematic and logical manner, ensure safe nursing practice, quality care, competent use of thinking skills, abilities for sound clinical judgments and safe decision-making [9].

Ideal critical thinker is habitually inquisitive, well informed, trustful, open minded, flexible, fair-minded in evaluation, honest, prudent when making judgement, willing to reconsider, clear, diligent in seeking relevant information, reasonable in the selection of criteria, focused in inquiry, persistent seeking results.

The specific steps which were from the studies of Fallis [11] on how to create a concept mapping which is based on the scenarios was presented to the students, though, the study did not discuss more on any other methods they applied during the introductory class session 
Page 3 of 5

apart from verbal presentation. Equally, they were divided in groups; the students completed six maps which were based on six scenarios and concepts from the Roy's Adaptation Model as cited by Advisor [12] dealing with physical functions (activity and rest, fluids and electrolytes, neuroendocrine, sensory perception, and sexuality) and their role functions $[13,14]$.

After the exercise, the researchers scoured the maps using the modified system based on the concept mapping scoring criteria by Novak and Gowin [15]. They were analyzed in four categories: concept links ( 2 points each), cross-links (10 points each), hierarchies (5 points each), and examples (1 point each). Thirty (30) was the highest score for a map. The whole draft of the concept maps for each group was scored. The study did not address who scored the highest and how many they were. "Proposition inventory" a qualitative evaluation tool was used in order, so as to be able "to account for the variation in the quality of concept maps" [15]. The tool was not described or the reliability or even the validity of it to either.

A concept is an actual consistency in events or objects labeled by a label. Concept maps are Novak and Gowin first introduced concept mapping in 1984 to facilitate the process of meaningful learning. They defined the concept map as a schematic diagram that represents key concepts in a framework of propositions. The authors also outlined criteria that can be used by nurse educator tools for organizing and representing knowledge in networks of concepts and linking statements about a problem or subject [15].

The central box or circle can be the patient with the Lines and arrows coming from the patient which can lead to medical and nursing diagnoses. Hence more added concepts such as symptoms, goals, interventions, and evaluation approaches can all be additional. It can become much too complex for a reader to decipher when too much information is added to a single concept map, another alternatives is to divide the task into two concept maps; one for care planning and one more for pathophysiology. If diagnoses, goals and interventions are placed in different shaped figures such as circles, octagons, and triangles it is sometimes easier to follow a care map.

There are multiple structures used for concept mapping which is to make certain that the concept mapping is used broadly in nursing education. Students may use them as a note taking or study tool. Thus, the nursing faculty may employ them as a teaching strategy in the classroom. Concept mapping is an effective way to teach learners on how to think approximately regarding concepts in addition to see the big picture of by what means details and variables in a condition appropriate together.

\section{Objectives}

In the nursing education, Concept mapping have been used as a method for students to organize and analyse data. This review article examines empirical studies on the use of concept maps as a compare students' level of understanding knowledge on concept mapping; the impact of training of concept mapping on students' confidence level in the clinical areas; Its implications to students' understanding on the application of knowledge in patient care using concept mapping in the clinical areas and students' satisfaction level learning through concept mapping in the clinical areas will also be discussed.

\section{Research Methodology}

\section{Design}

This is a classic experimental design with After Post-test Only Experimental Design. For this kind of designed as according to Nirmala et al. [5], the design is composed on two randomly assigned group but no pre-test is required before the time of implementation to both group,

As for this study the explanation for the above designs (classic experimental design with After Post-test only experimental design by Nirmala et al. [5]. In this particular study, the cause and effect relationship of students learning experiences through concept mapping will be determined from the experimental and the control group of 22 students in each group.

This study focuses only on post-test. A post-test would provide information on the outcome of concept mapping, especially the student's satisfaction level of learning in the clinical area.

\section{Study location}

The study was conducted at the KPJ Perdana Specialist Hospital (PdSH) in Kota Bharu, Kelantan. It is situated on the east coast of Malaysia. It is the 11th hospital under the care of KPJ Health Berhad, the health care division of Johor Corporation and one of the leading health care providers in Malaysia. The hospital was established in 2001, occupying an area of 87,802 sq.ft. It started operation for outpatient care in the year 2001 and inpatients in 2002, and has a maximum capacity of 124-beds with a daily inpatient capacity of 103 beds. As part of the inpatients and outpatients provided by the hospital, the multi-disciplinary care provided by PERDANA includes a host of upto date support facilities. The hospital has about seven departments which are medical, surgical, gynaecology, obstetrics, nursery, urology and orthopaedics

\section{Target population and sample}

The population of the study is nursing students of KPJ Healthcare University Colleges in Nilai and students from the KPJ International College, Johor Baharu. Those students were posted to KPJ Perdana Specialist Hospital, Kota Bharu, Kelantan for a clinical placement. When the study was conducted, 44 students were posted by both institutions to this hospital from January to July 2017. The sample population was the semester 8 population of the nursing students. However, since, the study will be conducted with only students at KPJ Hospital Kelantan; the sample may not be representative of characteristics, such as age, gender, ethnicity, of other campus of KPJ Colleges or other health colleges in Malaysia. This limits the ability to generalize the findings to the entire student population of KPJ other locations.

The collection of data runs from January to June 2017. The two groups of students from KPJUC and KPJIC will alternately perform the concept mapping approach of obtaining the learning experience in the clinical areas.

Students were randomly divided from the month of January to February 7 students from KPJUC will do the concept mapping and the 7 students from KPJIC will be the control group. Then followed by the month of March till April, 8 students from KPJUC will be the control 
and 8 students from KPJIC performed the concept mapping approach. The same thing goes into the month of May till June 2017.

\section{Inclusion criteria}

The studies provide useful information about concept maps being used in the clinical area in one of the private hospital in Malaysia. This study contain of the expenditure of concept mapping as an instrument that improve students' meaningful learning and knowledge in the clinical area, as a way to expand students' critical thinking skills. The inclusive criteria were student nurses in the final year or semester 8 from both institutions KPJUC and KPJIC placed in the KPJ Perdana Specialist Hospital to fulfil the 8 weeks clinical placement from January till June 2017.

\section{Exclusive criteria}

Nursing students from KPJUC and KPJIC of different semester placed in the KPJ Perdana Specialist Hospital to fulfil the 8 weeks clinical placement from January till June 2017.

\section{Results}

\section{Data extraction and analysis}

The researcher analyzed the data using the IBM SPSS version 23 software. Descriptive statistics were measured for the following variables; 1) understanding on the concept mapping, 2) impact of training, 3) application of knowledge, and 4) evaluation on concept mapping.

\begin{tabular}{|c|c|c|c|c|c|c|c|c|c|c|c|c|}
\hline \multirow[t]{2}{*}{ Component } & \multicolumn{3}{|c|}{$\begin{array}{l}\text { Understanding of concept } \\
\text { mapping }\end{array}$} & \multicolumn{3}{|c|}{ Impact of training } & \multicolumn{3}{|c|}{ Application of knowledge } & \multicolumn{3}{|c|}{$\begin{array}{l}\text { Evaluation } \\
\text { mapping }\end{array}$} \\
\hline & Sum & M & SD & Sum & M & SD & Sum & M & SD & Sum & M & SD \\
\hline Traditional method & 554 & 26.38 & 4.86 & 893 & 42.52 & 6.74 & 894 & 42.57 & 7.91 & 952 & 45.33 & 6.27 \\
\hline $\begin{array}{l}\text { Concept mapping } \\
\text { method }\end{array}$ & 812 & 36.91 & 3.25 & 1050 & 47.72 & 3.51 & 1108 & 50.36 & 3.5 & 1117 & 50.77 & 4.32 \\
\hline
\end{tabular}

Table 1: Descriptive statistics to measure the scale with four objective of question.

The above Table 1 shows descriptive statistics of the four variables; understanding of concept mapping, impact of training, application of knowledge and evaluation on concept mapping. The first descriptive statistics measures understanding of concept mapping shows the traditional method sum is 554, mean 6.38 and the SD 4.86 while in the concept mapping methods for understanding of concept mapping displays sum of 812 , mean 36.91 and SD 3.25. This show mean for concept mapping is higher as 36.91 compared with the traditional method which is 26.38 .

Meanwhile from the Table 1 above it shows that in the impact of training, the sum for the traditional method is 893 and the sum for concept mapping is 1050. Mean for traditional method is 42.52 and the mean for concept mapping 47.72. This was followed by the SD for traditional method is 6.74 and $\mathrm{SD}$ for concept mapping group is 3.5. The results of mean shows that the mean for concept mapping is higher than the mean for traditional method group.

Descriptive statistics for the next variable is application of knowledge. The sum for the traditional method is 894 and for concept mapping method the sum is 1108 . The SD traditional method is 7.91 and the SD for the concept mapping method is 3.50. Mean for traditional method is 42.57 and the mean for concept mapping method is 50.36. These appearances that the mean for concept mapping is higher than the traditional method.

Furthermore, for the scale with fourth objective of question on evaluation of concept mapping sum traditional method is 952 and concept mapping method 1117. The traditional method SD is 6.27 and the concept mapping is $4: 32$. While the mean for traditional method is 45.33 compared to concept mapping that is 50.77. It is shows the concept mapping approach are better because the mean is higher than the traditional method.

\section{Discussion}

Concept mapping have been used to serve as directional aids for hypermedia, as a support for understanding, for association of educational experiences found in such ways such as to improve affective conditions for learning, as assistance or another to out-of-date writing, in developing the critical thinking skills.

The chapter is the discussion of the study on the level of understanding knowledge, Impact of training on student's confidence level, Application of knowledge into patient care and evaluation of the application of concept mapping in the clinical areas.

Further down is the discussion about clinical evaluation of learning experience on concept mapping for final year nursing students in a clinical placement.

In this study, $44(100 \%)$ of the survey were successfully returned. This is considered as a representative of the population. Most of the respondent's demographic characteristics distribution reflects the distribution of the population. The rate of the respondent was also higher than previous research with similar field.

Furthermore with the higher rate of the respondent in order to answer the research objectives, the summary of the findings was divided into a few sections. Those sections were:- (1) Descriptive statistics to measure the scale with four objective of question (2) General knowledge of group exposed to concept mapping and those exposed to traditional (3) Students' understanding on the application of knowledge into patient care using concept Mapping in the clinical areas and those exposed to traditional (4) Students confidence level in the clinical areas on concept mapping and traditional method (5) Level of satisfaction learning using concept mapping and traditional method in clinical setting area.

Based on the findings of the study, nursing educators should design and evaluate teaching strategies that will enable nurses to develop these 
Citation: Tiap OS, Hassan H, Tee MH, Mohd Rosli RA (2018) Evaluation of Clinical Learning Experience on Concept Mapping for Final Year Nursing Students in a Private Hospital. J Nurs Care 7: 465. doi:10.4172/2167-1168.1000465

Page 5 of 5

cognitive and conceptual abilities, which will lead to improved performance and patient care outcomes. Focusing on educational strategies, such as concept mapping, appropriate to the learning needs of novice and advanced beginner nurses, facilitates the transformation of novice nurses into competent professionals.

\section{Conclusion}

Concept mapping is such a strategy of learning or teaching. It is not a complete illustration of the significant concepts and ideas the learner knows. A students and instructors can purposefully expand, to meaningful learning and critical thinking. Student can understand the teaching and retention will be enriched with meaningful learning. Concept maps can be used to help the students pre-identify key concepts and relationships.

Students need to be introduced to their format, their application, their construction and convinced that maps will help them see the nature and role of concepts and the relationships that exist. The aim of concept maps is to help students learn how to learn. Concept maps have been used successfully in teaching and planning instruction in English literature, mathematics, music, science, and engineering. They can become a useful strategy in instructing nursing students in the classroom and clinical settings.

\section{References}

1. Papastavrou E, Dimitriadou M, Tsangari H, Andreou C (2016) Nursing students ' satisfaction of the clinical learning environment: A research study. BMC Nurs pp: 1-10.

2. Dale B, Leland A, Dale JG (2013) What factors facilitate good learning experiences in clinical studies in nursing: Bachelor students perceptions. 2013: 1-7.
3. Lamartina K, Ward-smith P (2014) Developing critical thinking skills in undergraduate nursing students: The potential for strategic management simulations 4: 9 .

4. Clayton LH (2006) Concept mapping: An effective, active teachinglearning method. Nurs Educ Perspect 27: 197-203.

5. Nirmala T, Shakuntala BS (2011) Concept mapping- An effective tool to promote critical thinking skills among nurses 1: 1-5.

6. Nirmala T, Shakuntala BS (2012) Attitude of students on concept mapping - An innovative teaching learning strategy. Nitte Univ J Heal Sci 2: 39-43.

7. Brullo A (2009) Concept maps facilitating note taking: Adding know-how to knowledge.

8. Hinck SM, Webb P, Sims-Giddens S, Helton C, Hope KL, et al. (2006) Student learning with concept mapping of care plans in communitybased education. J Prof Nurs. 22: 23-29.

9. Kostovich CT, Poradzisz M, Wood K, O’Brien KL (2007) Learning style preference and student aptitude for concept maps. J Nurs Educ 46: 225-231.

10. Pudelko B, Young M, Vincent-Lamarre P, Charlin B (2012) Mapping as a learning strategy in health professions education: A critical analysis. Med Educ 46: 1215-1225.

11. Fallis A (2013) How to create a concept mapping. J Chem Inf Model. 53: 1689-1699.

12. Advisor BK (2012) The effectiveness of concept mapping as an educational tool.

13. Atay S, Karabacak Ü (2012) Care plans using concept maps and their effects on the critical thinking dispositions of nursing students. Int J Nurs Pract 18: 233-239.

14. https://teach.its.uiowa.edu/sites/teach.its.uiowa.edu/files/docs/docs/ Concept_Map_Rubrics_ed.pdf

15. Novak JD, Cañas AJ (2008) The theory underlying concept maps and how to construct and use them. CMAP 1: 1-36. 